\title{
Poisoning and re-introduction of the Griffon Vulture Gyps fulvus in Kresna Gorge, Bulgaria 2017
}

\author{
Hristo Peshev ${ }^{1 *}$, Emilian Stoynov ${ }^{1},{\text { Nadya } \text { Vangelova }^{1} \& \text { Atanas Grozdanov }}^{2}$ \\ ${ }^{1}$ Fund for Wild Flora and Fauna, Bulgaria \\ ${ }^{2}$ Sofia University "St. Kliment Ohridski", Bulgaria \\ *Corresponding author: hristopeshev.eu@gmail.com
}

http://dx.doi.org/10.4314/vulnew.v75i1.2

\section{Summary}

The reintroduction of the Griffon Vulture Gyps fulvus in Kresna Gorge in south-western Bulgaria started in 2010 (Stoynov \& Peshev 2011, 2012, 2013, 2014) and is run by the Fund for the Wild Flora and Fauna (FWFF). At present it is part of the project "Vultures Back to LIFE". The number of wintering Griffon Vultures during the winter season 2016-2017 was a record high: 50 birds with some counts of over 60. About 10 pairs were showing breeding behaviour and at least four eggs were laid, until mid-March 2017 when the largest documented poisoning event of Griffon Vultures in the Balkan Peninsula occurred.

From 12 March 2017 to early April of that year, the bodies of 18 Griffon Vultures were found, and the missing and indirectly identified victims numbered more than 30 individuals. Although several cases of poison baits targeted to kill wolves were recorded near the villages of Stara Kresna, Krupnik and Tserovo, all the vultures were poisoned probably in the same place near the village of Tserovo over at least three consecutive stages. While small baits were used in the first two regions and affected mostly wolves, foxes, and dogs, in the area of Tserovo the poison was set in a carcass of a dead cow that remained an active bait on the ground for more than two weeks. Despite the wide media coverage and mass public response to this destruction of nature, law enforcement investigations did not result in any prosecutions.

The incident marked 2017 year as a catastrophe for the colony of Griffon Vultures in Kresna Gorge. Birds from other colonies were killed too: several birds from Vrachanski Balkan, including the first marked chick from a nest in the region, a bird from the Eastern Rhodopes and several from Macedonia and Serbia.

High levels of management effort, combined with an increasing knowledge of the species and applied by FWFF and related organizations, resulted in the Kresan Gorge colony reconsolidating and being sustained. The remaining five to eight birds, probably with memory of the colony of Kresna Gorge, were supported by the immediate release of six more Griffon Vultures and by the continuous provision of safe food at vulture feeding sites. By the end of 2017, the local group of vultures ranged in size between 15 and 35 birds. For the monitoring and possible prevention of poisoning, the use of precise and intensive data collection via satellite transmitters was introduced. 
Poisoning of approximately 30 Griffon Vultures in Kresna Gorge - Timeline March 2017.

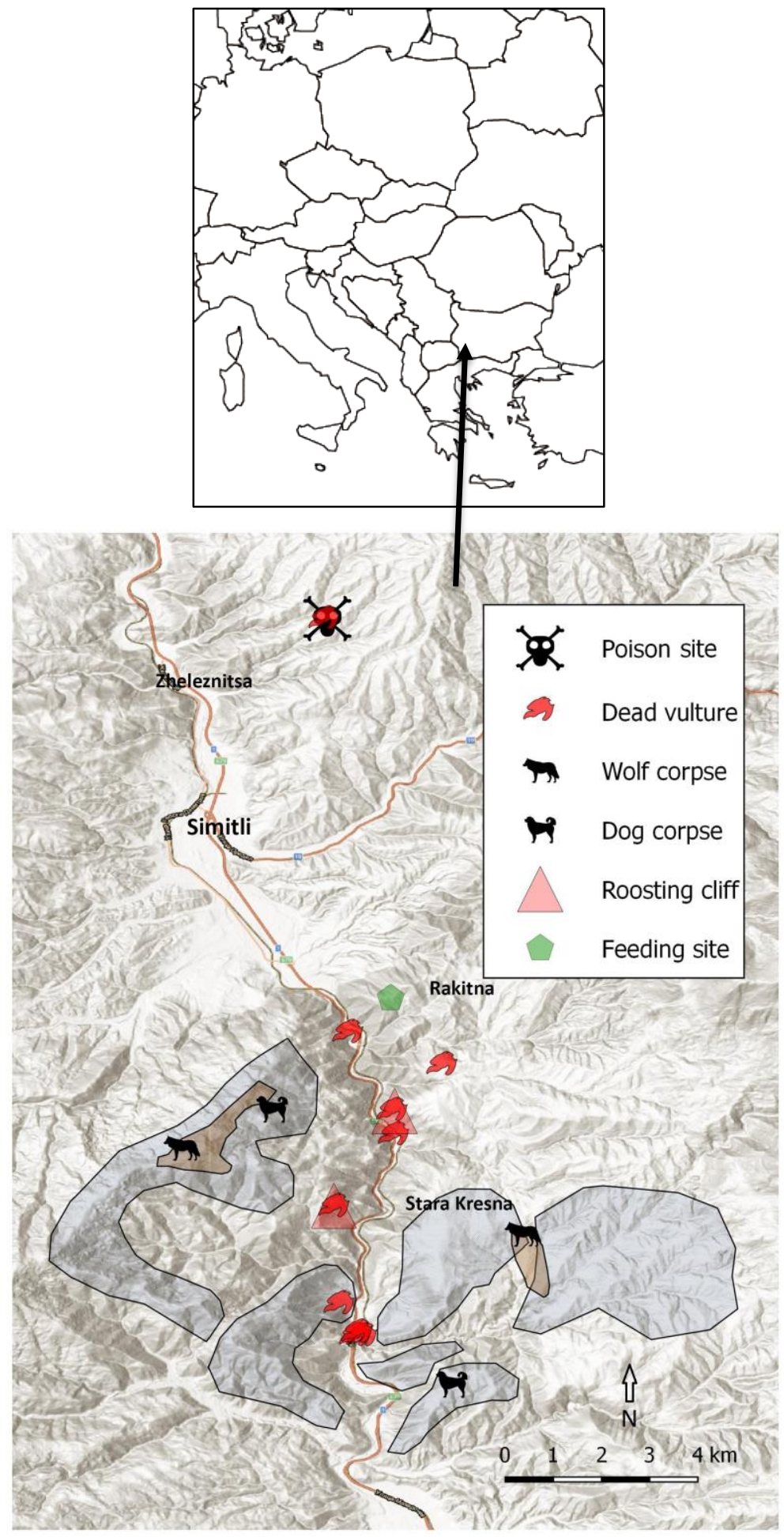

Figure 1: The study site and location of Kresna Gorge in western Bulgaria.

In early 2017 the number of Griffon Vultures in from other colonies had joined for the winter. The Kresna Gorge was at a record high, with up to 60 winter had been cold and snowy weather led to individuals being counted (Figure 1). Vultures large livestock losses and thus plenty of food not 
only at the feeding site (where nearly 10 tons were deposited in February 2017), but also around the villages in the region. A record number of birds was showing breeding behaviour was identified, with 10 pairs in two distinct colonies, or breeding sites.

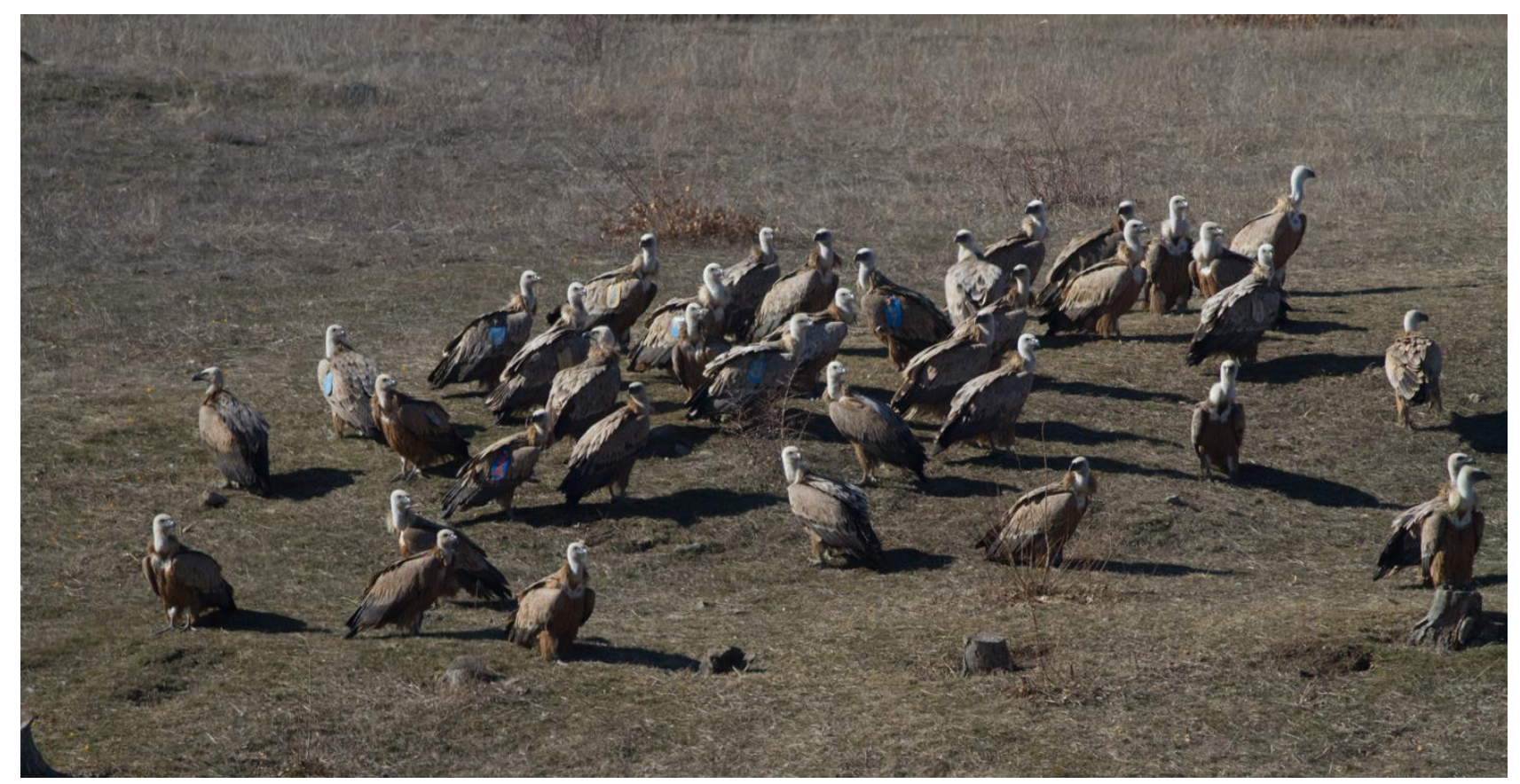

Figure 2: Vultures near the feeding site in the Kresna Gorge, Bulgaria, January 2017.

\section{2th March 2017}

FWFF received a message about a Griffon Vulture found in Tisata Reserve by rangers of Pirin National Park. On site, the team discovered that this was the bird with wing-tag 56 , which appeared as being in bad condition, with paralysed legs. The veterinarian of Kresna applied atropine to the bird, although poisoning was not yet seriously considered as the likely reason for the condition of the vulture. The bird 56 had a full crop of food, but was not vomiting even with the stress of human presence and during the manipulations that were being done to treat it. X-rays excluded other types of trauma or shooting as reasons for the bird's condition. Most of the birds in the colony were still observed at the roosting sites and a lot of food was still available at the feeding site. 


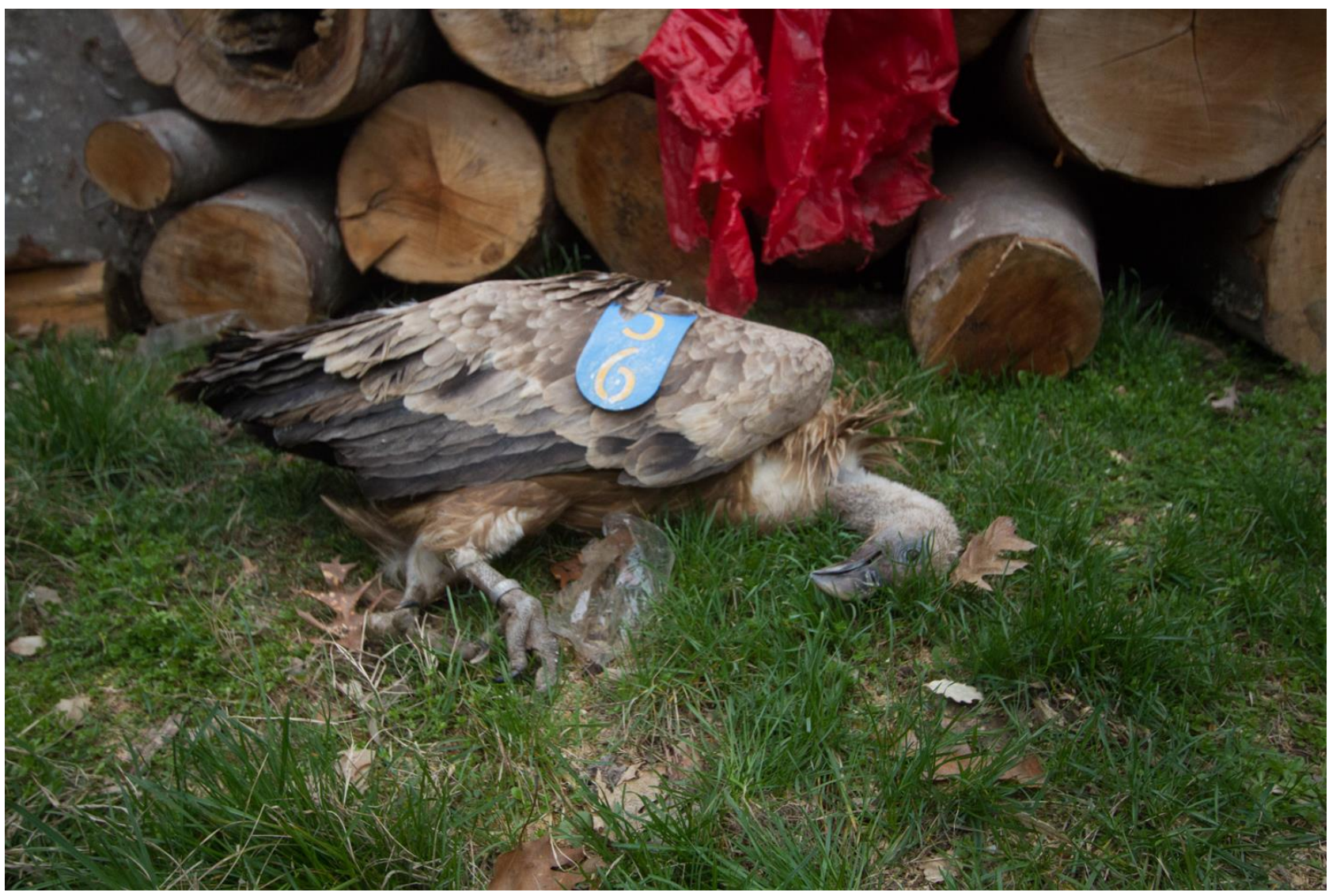

Figure 3: Vulture 56 in the yards of the Pirin Park rangers. Kresna Gorge, Bulgaria.

\section{$13^{\text {th }}$ March 2017}

A dead vulture was reported not far from the place the first one was found the previous day. This bird also had a full crop, and thus poisoning was now considered to be the reason for the observed situation. Police, environmental inspectors and veterinary services were alerted. The need to obtain permissions from several institutions delayed the arrival and several officials were appointed to visit the site next morning. The FWFF team visited the site and took pictures of the bird. The vulture was with full crop, but showed no signs of vomiting.

The FWFF team tried to inform as many people as possible in nearby settlements, with the aim of alerting the poisoner to what was happening so they might collect and remove the bait, hopefully to prevent further poisoning of vultures.
At the same time, the FWFF team launched a search of all areas within a radius of $4 \mathrm{~km}$ from the place where the dead birds were found. The mayor of the near-by village Stara Kresna reported a missing dog and dead fox in the vicinity of the village, but any poisoned bait was still undiscovered. A number of birds - up to 23 - were still being observed at roosting sites and at the feeding site. Three captive bred birds were placed into an aviary at the feeding site, to serve as attractants to the wild vultures, with an aim of bringing them to the feeding site instead risk being poisoned.

\section{$14^{\text {th }}$ March 2017}

The institutions visited the site and completed incident fact sheets. The veterinarians took the corpse for autopsy in Blagoevgrad, and sent 
samples for analysis to a toxicology laboratory in Sofia. These results showed only they have reagents only for the most common types of pesticides - the carbamate/organophosphate group. A dead dog was found $3 \mathrm{~km}$ south of the poisoned vultures. At the same place was a case of poisoned dogs in 2015.

\section{$15^{\text {th }}$ March 2017}

A dead wolf was found near the village of Stara Kresna. The FWFF team managed to bring only a representative of the Regional Inspectorate for Environment and Water to the site. Free-range herds and dogs were observed in the searched areas, obviously not affected by poisoning. The number of vultures in the colony in the coming days was about 32-33. The poisoned vulture (\#56) that was the first to be found on March $12^{\text {th }}$ was recovering well.

\section{$17^{\text {th }}$ March 2017}

A sick raven (Corvus corax) was observed around the feeding site. The search for the bait continued and all the stakeholders and local counterparts were alerted to provide information about any dead animals or baits that were found.

$20^{\text {th }}$ March 2017

The toxicology laboratory advised that the samples sent for analysis were positive for carbamate/organophosphate pesticides. FWFF received a new alert from Pirin National Park that rangers have found a poisoned vulture at the same place where the previous two were found.

\section{$21^{\text {st }}$ March 2017}

The site was visited by representatives of the institutions except for the police, they refused, as parliamentary elections were due. The two vultures were with full crops fallen near the Struma river, most likely looking for water. Again samples were sent for testing.

\section{3rd March 2017}

A dead vulture with a blue wing-tag was spotted high on the cliffs in the Kresna gorge. The search for the poisoned bait continued across as wide area. Ravens were found dead at the feeding site.

\section{5th March 2017}

The Griffon Vulture C was found dead under the pylons between villages of Rakitna and Mechkul, where the birds sometimes roost. A second poisoned wolf was reported in the mountain above Krupnik. Vultures are no longer seen in the Gorge, except the two incubating females.

27th March 2017

The Griffon Vulture K was found dead in the Gorge near the river and the roosting cliff. 


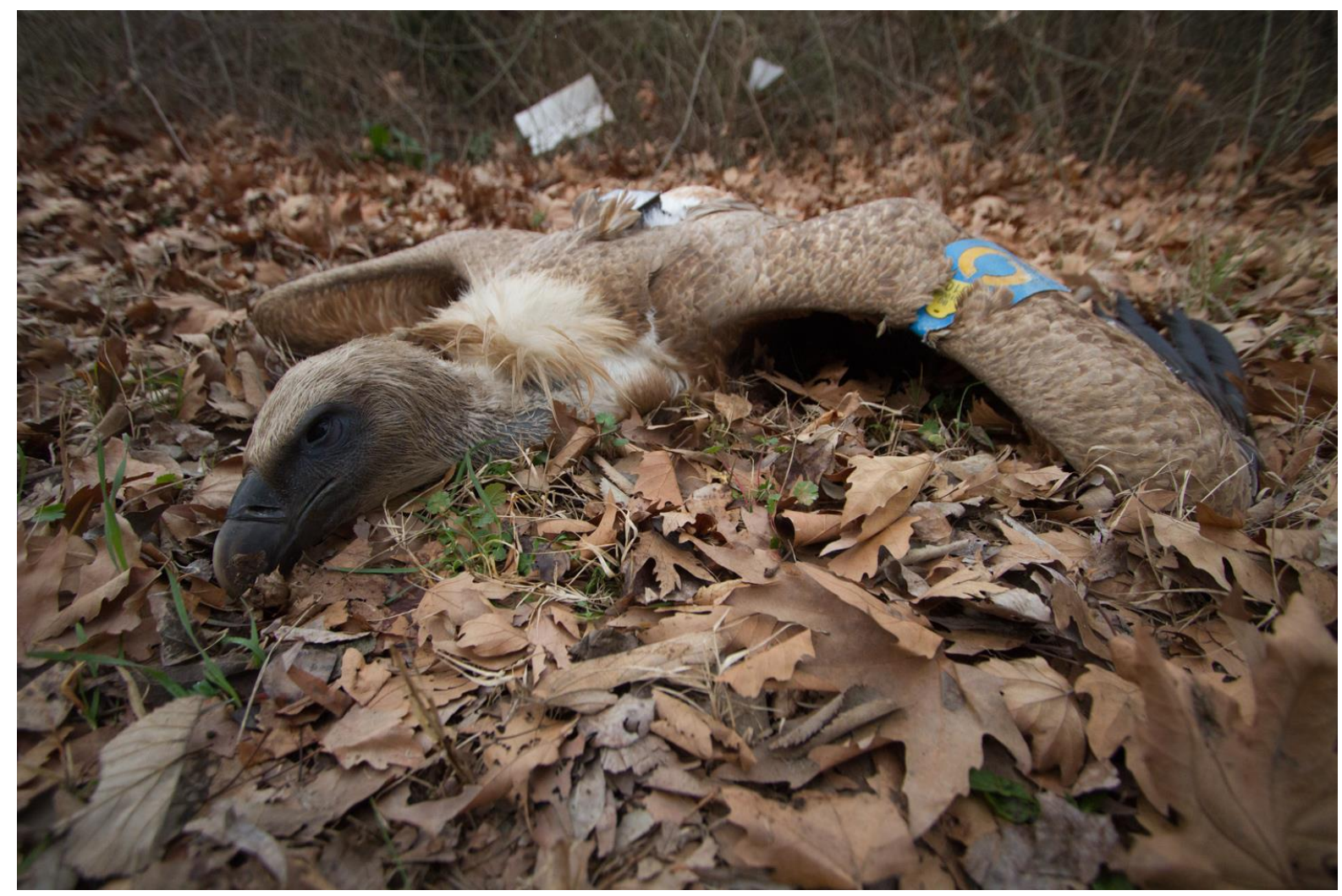

Figure 4: Vulture 9

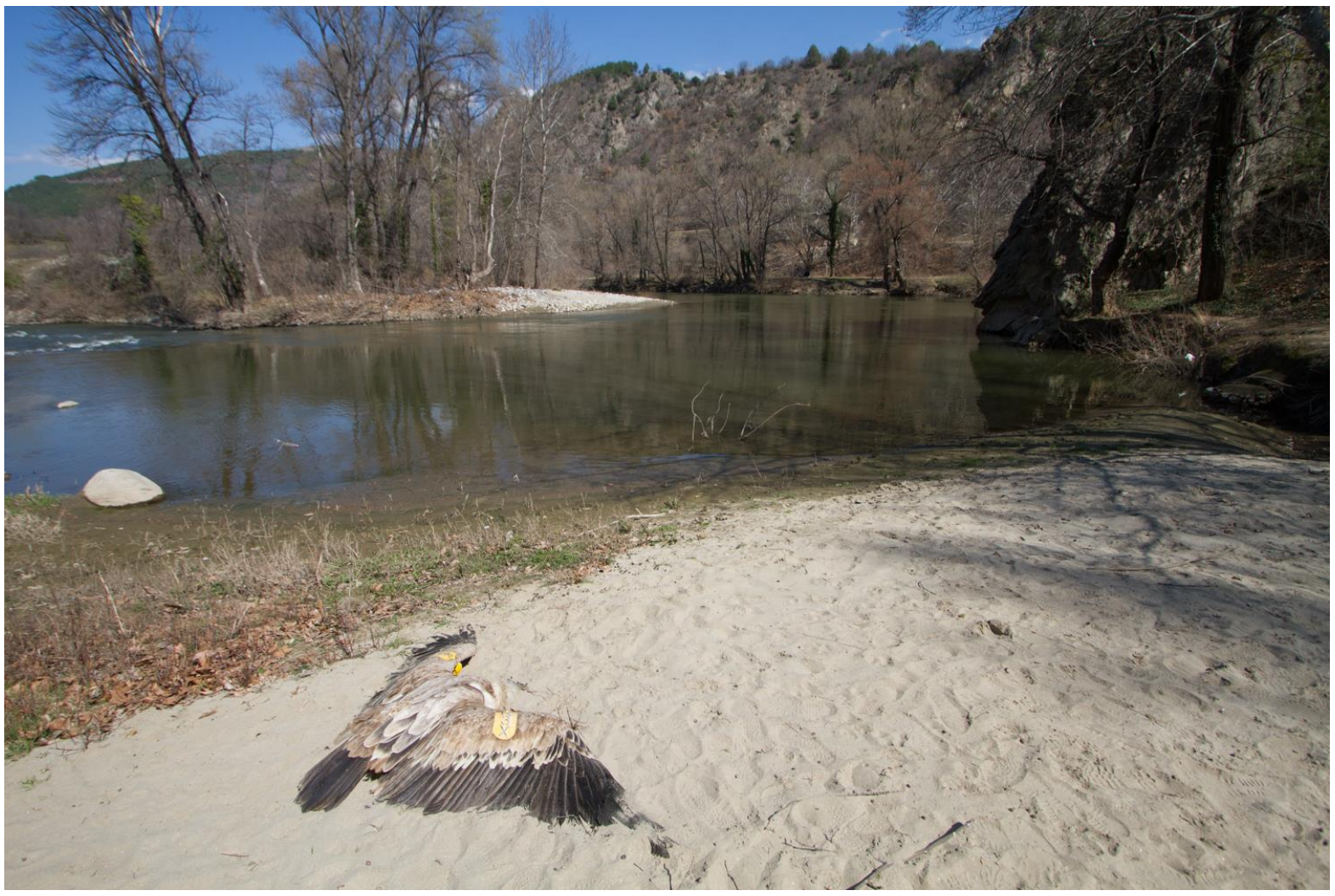

Figure 5: Vulture K3X, poisoned in the Kresna Gorge, Bulgaria 
An attempt was made to feed the female B61 in the nest as her chick has just hatched. During the visit of the cliff two more dead vultures were found.

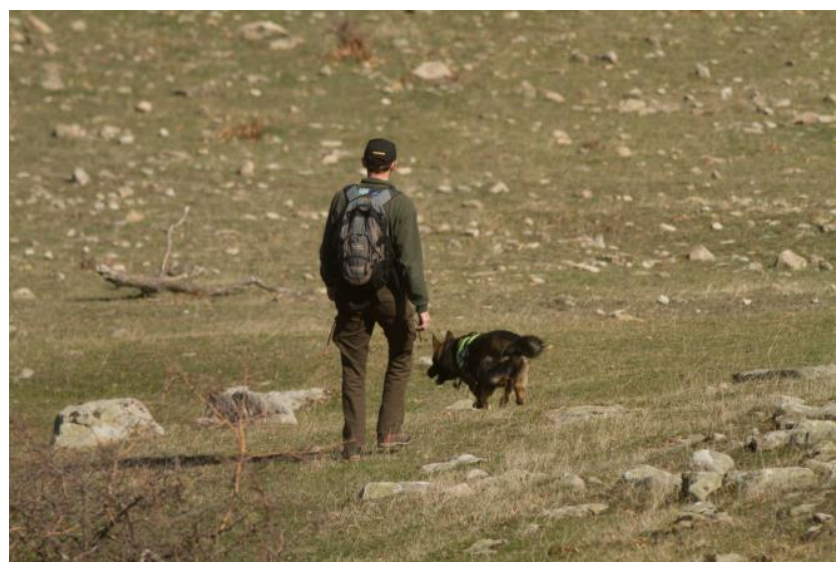

The BSPB's Poison Dog Unit was working on the ground. The vast area did not allow us to locate the poison, and this reduced the effectiveness of the dog. Several marked vultures were observed. Reading their wing-tags showed that they were new birds in the Gorge.

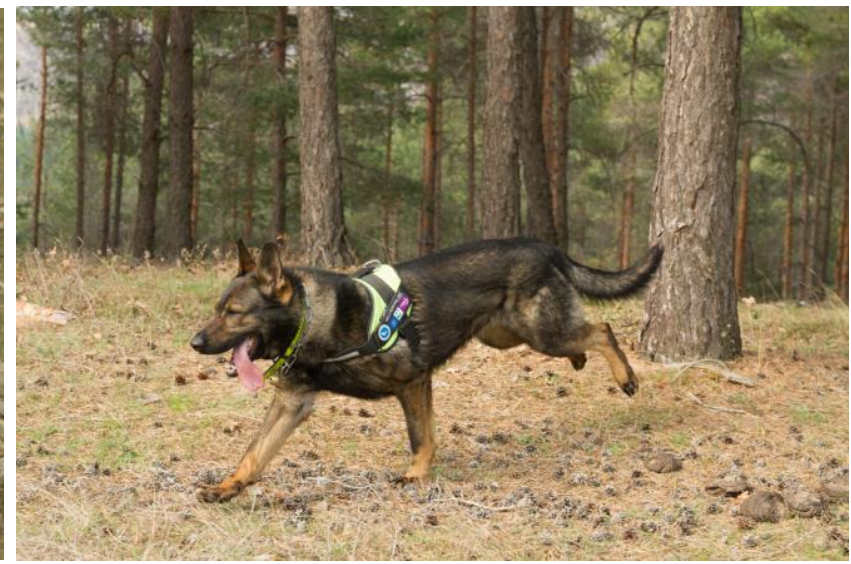

Figure 6: The BSBP Anti-Poison Dog Unit in action.

$2^{\text {nd }}$ April 2017

An alert was received about the remains of a dead cow and vulture corpses through the Forestry Service and the Environment Inspectorate in Blagoevgrad. Three dry corpses of Griffon Vultures were found around a dry corpse of a large cow. All the corpses were located $20 \mathrm{~km}$ north from the place where the first two corpses of dead vultures were found and $10 \mathrm{~km}$ north from the feeding site. Many dead insects were found in the stomach contents of the cow. The FWFF team also received information about a dead wild boar in the area.

$3^{\text {rd }}$ April 2017

The authorities of all the institutions were taken to the site of the dead vultures and cow, incident fact-sheets were completed and samples were taken, testimonials were provided to the police department.

\section{$4^{\text {th }}$ April 2017}

After a thorough check of all known roosting sites, six more vultures were found. Later in the day three more were found by volunteers and the FWFF team. In total, 18 dead vultures were found and about another 30 birds were missing. Only six Griffon Vultures were observed at the feeding site.

$5^{\text {th }}$ April 2017

The poison bait was finally found and it was clear it was no longer active, thus a rescue mission for the chick and the egg from the two nests under observation was organised. After removing the poison bait, the females were safe and they could leave the nests. The chick of one nest (B61) was 
missing; the egg of Griffon nest 5 was collected and transferred to the Wildlife Centre of Green Balkans in Stara Zagora.

\section{The situation after the poisoning incident}

The poisoning incident directly ruined the colony and even the non-breeding nucleus of Griffon Vultures in the area was nearly destroyed. The two known pairs incubating eggs lost their partners and thus the breeding season for them was compromised. Overall, in April 2017 about five to eight birds from the colony and nonbreeding birds from the nucleus in Kresna Gorge remained alive, while some of the visiting birds had dispersed.

To boost the nucleus population, the FWFF team firstly released three, and later another three, Griffon Vultures fitted with GPS/GPRS transmitters. At the same time, the local migration of the species started and the flow of birds on passage through the area increased to around 14-20 vultures. A number of birds that had been missing for some time arrived back in the area (e.g. the very first chick fledged in Kresna Gorge in 2016 - B74-XX) and it seemed that the colony/nucleus was becoming reestablished. Over the following months movement of birds to Demir Kapia colony in FYR Macedonia (FYROM) and back to Kresna Gorge was very intensive. Nature Conservation Association "Aquila" (NCA Aquila) intensified the provision of food for the vultures at the feeding site at Vitachevo, with the aim of attracting as many birds as possible from Kresna Gorge in order to keep them away from the poison in the area for a while.

The frequent communication and the usage of the two feeding sites - Vitachevo in FYR Macedonia and Kresna Gorge in Bulgaria, was demonstrated by the GPS/GPRS transmitters, and some birds were moving between the two sites daily. Breeding birds in Demir Kapia were also coming to take food at the feeding site in Kresna Gorge. Additionally, with the help of non-breeding wild Griffons captured and tagged with GPS/GPRS in Kresna Gorge, a small new colony was discovered in FYROM in the area of Chatino, south from the Vitachevo feeding site. This new colony of just two to three pairs was confirmed by Emanuel Lisichanets from NCA Aquila, in addition to the 10 pairs at Demir Kapia, bringing to 12-13 the number of pairs that bred in FYROM in 2017.

A minimum of 130 different Griffon Vultures were observed in Kresna Gorge later in 2017, including those released as part of the project, in addition to migrating, vagrant, wintering or summering birds from other parts of the Balkan Peninsula. Marked birds from Israel, Greece, Serbia, Croatia and other parts of Bulgaria have also been observed and, for the first time on record, a Griffon Vulture originating from Spain arrived on its own was observed at the feeding site in Kresna Gorge on 29 September 2017. This bird (8A6) had been rehabilitated in Burgos, Spain as a juvenile in 2007 and 10 years later appeared in Kresna Gorge.

Conversely, birds released in Kresna Gorge have been observed in Serbia, Greece and FYROM as well as other parts of Bulgaria (Vrachanski Balkan, Sinite Kamani, Central Balkan, Kotel, and Eastern Rhodopes).

As in previous years, the Griffon Vultures spent the hottest summer months in Pirin National Park and sometimes in Rila National Park. A summering group of Griffon Vultures from Mariovo and Demir Kapia regions in FYROM was once again observed in Kaymakchalan - a large, high altitude $(>2,500 \mathrm{~m})$ and treeless zone, full of free-ranging livestock. Congregations of summering Griffon Vultures in this area have been reported previously, and now confirmed by the movements of GPS/GPRS tracked birds and visits to the area by Pantelis Konstantinou and Hristo Peshev. 
In 2017, GPS/GPRS tracked Griffon Vultures captured and marked in Kresna Gorge were recorded for the first time summering in the Central Greek Mountains. One tracked bird $(\mathrm{OX})$, released in Kresna Gorge after summering on Kaymakachalan and Mariovo area of the FYROM/Greek border, moved for wintering to the Akarnanika - Baumistos Mountains southwestern Greece, which appears to be a good place for wintering of the species in recent years. Unfortunately, some cases of poisoning were reported from the area (Rigas Tsiakiris - in litt.).See: https://www.4vultures.org/the-silentkiller-strikes-again/

The presence of Griffon Vultures and the feeding site are likely reasons for attraction and observations of other rare and threatened species in the area like the Eurasian Black Vulture Aegypius monachus and the Egyptian Vulture Neophron percnopterus. For example, an immature Eurasian Black Vulture was observed and photographed in flight with a large group of Griffon Vultures on 15 February 2017 in Kresna Gorge. On 5 May 2017 an adult Egyptian Vulture was observed in Kresna Gorge. This species was spotted again in June 2017, and a picture from a camera trap at the feeding site of an immature bird was taken on 6 August 2017.

\section{Conclusions}

Despite the great loss from the poisoning incident (the biggest recorded in Balkans), the Griffon Vulture nucleus in Kresna Gorge was saved and it was successfully re-established. The colony now is integrated to Demir Kapia colony and forms a common Griffon Vulture population across FYROM and SW Bulgaria.

The following factors were important: a) the presence of surviving birds that kept alive the social memory for the colony and connections with other sites;

b) the presence of floating/drifting birds from other source populations like Uvats in Serbia and Eastern Rhodopes in Bulgaria;

c) the presence of active colonies in FYROM (Demir Kapia and Chatino) only about 90-100 km from Kresna Gorge.

Some more factors (listed below) were crucial and their application in Kresna Gorge is likely to have made the difference between reestablishment of the colony or its extinction due to poisoning, or its inability to be re-established similar to Nestos Gorge Griffon Vulture colony in Greece. The Nestos Gorge colony had the first three factors listed above in place, but important missing factors that were relevant to Kresna Gorge were:

d) a concentration point. The feeding site plus the aviary containing Griffon Vultures kept close to suitable roosting sites;

e) The release of some more birds very soon after poison bait was found and removed, to supplement the local population nucleus;

f) Trans-border cooperation of dedicated teams and coordinated feeding sites maintenance.

After the poisoning incident, we reached the following conclusions:

1. There should always be about $10 \%$ of the birds in the colony tracked with GPS/GPRS transmitters, to know where they go to feed and to react urgently if a poisoning is suspected. Despite the ability of the Anti-Poison Dog Units to check certain areas for poison baits and/or dead animals, there is need for preliminary information and the general location of the poisoning event. This preliminary information could be received as reports from local people or tourists, but the best option would be to keep 
a certain number of "poison spy agents" among the vultures in the local community - such equipped with latest generation of GPS/GPRS transmitters.

Transmitter data should be checked several times a day, which with new technologies (smartphones, laptops) is very easy. In case of atypical behaviour of the bird (for example, staying for a long time in an unsuitable place or a signal showing that the vulture is not moving), measures can be taken to verify and check the location (ideally with an Anti-Poison Dog unit). Where a dead vulture it is found, it is important to check the points where the bird has stopped in the previous 24 hours. This not only gives data about the particular bird but also in the presence of a poisonous bait prevents the poisoning of other vultures.

Informing local farmers that the birds are being monitored with transmitters, combined with fieldworkers regularly checking for incidents, can potentially discourage people from using poisoned baits.

The effectiveness of this system was confirmed more recently with a case of poisoning in the Pindus Mountains in western Greece in May 2018. Two vultures with transmitters from the Kresna Gorge moved there after wintering in the Eastern Rhodopes. One of the transmitters signalled a lack of motion. Unfortunately, the great distance did not allow an immediate check to be done, but at the exact coordinates our team found a dead vulture. After informing the Greek environmentalists and authorities, they visited the coordinates of the last locations of the bird with a trained dog; two more dead vultures were found and a calf used as a bait.

2. Never keep the acclimatization aviary empty of Griffon Vultures, as they attract the entire colony and any newcomers to the safe place to feed.

3. Never remove a carcass on which vultures have fed so far, but add a new one. Especially in cases where the aim is to attract the birds to the feeding site. Vultures often prefer to feed on a carcass they have fed on earlier.

4. The Anti-Poison Dog Unit is useful, but its effectiveness will be improved once a GPS tracking system is put in place.

5. Preserving the social memory of a colony is very important. In case of declining a colony, the social memory should be consolidated by intensive feeding, site maintenance and the release of birds to attract and fill up the minimum population nucleus of 8-12 Griffon Vultures.

\section{Conservation Actions}

\section{Immediate: Feeding}

In 2017 FWFF continued to organise feeding of vultures at a minimum three to four times per week (and every time carcasses are available sometimes up to seven days a week). More than 54 tons of carcasses were deposed in 190 events at the feeding site in 2017. In addition to the vulture feeding programme of FWFF in Kresna Gorge, food was also provided to Viatchevo vulture feeding site in FYROM by the Nature Conservation Association "Aquila". Food was provided there at least once a week, which encouraged occasional foraging movements of small groups of vultures between the two feeding sites. Feeding sites in the high mountain areas of Rila and Pirin National Parks should be established, as these areas are obviously preferred by the vultures in summer, and lesser risk of poisoning or electrocution exists there.

\section{Immediate: Insulation of dangerous power-lines}

In 2017 following two electrocutions of vultures in 2016, another seven $20 \mathrm{kV}$ power-line poles were equipped with perch discouragers, as an urgent measure to avoid future electrocutions of vultures. 
Long-term: Restoration of food source for vultures

The action for reintroduction of the Fallow deer in the area continues and FWFF continues to keep a herd of Rhodope Short Horn Cattle in Kresna Gorge. More and more farmers are interested to start raising this breed, given it has proven very adaptable and good for the area (forage use and predators protection).

\section{Long-term: Anti-poison activities}

The compensation programme (for stock loss due to predation) and the public awareness activities are continuing. However, it seems that feeding site operation in an area with a permanent wolf presence is the most effective anti-poison tool. Maintaining permanent feeding sites for vultures in regions of sympatric presence with wolf is an irreplaceable conservation tool. The existence of an aviary with Griffon Vultures inside, placed just at the feeding site increases the attraction of wild and free-ranging reintroduced vultures and is a way of keeping them away of occasionally present and potentially dangerous (poisoned) food. Poisoning is still hard to control along Struma Valley and this will always be the case until people and predators share the same habitat without conflict. Therefore, feeding vultures at traditional feeding sites is essential, while measures for minimising the use of poison baits are underway as permanent and long-term measures.

\section{Long-term: release of birds}

Releases of immature Griffon Vultures should continue with at least 10 birds per year until natural colony is established and begin to produce by ten juveniles per year.

\section{Acknowledgements}

The conservation work and monitoring of the vultures continue under the LIFE project "Bright future for the Black Vulture" LIFE14 NAT/BG/649, financed by the LIFE+ financial instrument of EU. The other associated beneficiaries within the Project are FWFF, Green Balkans, Vulture Conservation Foundation (VCF), Junta de Extramadura and EuroNatur. Additional financial contributors of the Project are BIOPARC Zoo de Doue and Sainte Croix Zoo from France and Nickelson Trust from Ireland. At the pre-release stage the project was financially supported by: Deutche Bundesstiftung Umwelt (DBU), Frankfurt Zoological Society (FZS), Foundation Ensemble, Rufford Small Grants (RSG), Whitley Fund for Nature (WFN), Black Vulture Conservation Foundation (BVCF), EAZA Carnivore initiative and others. We are grateful to GREFA and Spanish Government as well as Hegalaldia Wildlife Center and French Government for the rehabilitated Griffon Vultures provided for release. We are grateful also to Bioparc Zoo de Doue, Zoo Mulhouse, Zoo Sainte Croix and Paris Zoo from France as well as Barcelona Zoo from Spain for the provided captive bred Griffon Vultures for release. We are also grateful to all colleagues and nature lovers that provided information for observed Griffon Vultures: Blagoi Stefanov; George Stoyanov; Elena Kmetova; Lachezar Bonchev; Theodora Skartsi; Sylvia Zakkak; Volen Arkumarev; Marin Kurtev; Club SKOREC- Faculty of Biology/Sofia University; Rosen Aleksov; Goran Susic, Croatia; Sasa Marinkovic, Ohad Hatzofe, Hans Wilpstra. 


\section{References}

Stoynov, E., Peshev H. 2011. Re-introduction of Griffon Vulture (Gyps fulvus) in Kresna Gorge of Struma River, Bulgaria, Annual Report 2010, Fund for Wild Flora and Fauna, Blagoevgrad.

http://www.fwff.org/programs-2/welcome-back-home-2010-2020-decade-of-reintroductionoflocaly-extinct-species-in-bulgaria/griffon-vulture-reintroduction-in-kresna-gorge/

Stoynov, E., Peshev H. 2012. Re-introduction of Griffon Vulture (Gyps fulvus) in Kresna Gorge of Struma River, Bulgaria, Annual Report 2011, Fund for Wild Flora and Fauna, Blagoevgrad.

Stoynov, E., Peshev H. 2013. Re-introduction of Griffon Vulture (Gyps fulvus) in Kresna Gorge of Struma River, Bulgaria, Annual Report 2012, Fund for Wild Flora and Fauna, Blagoevgrad.

Stoynov, E., Peshev H. 2014. Re-introduction of Griffon Vulture Gyps fulvus in Kresna Gorge of Struma River, Bulgaria, Annual Report 2013, Fund for Wild Flora and Fauna, Blagoevgrad. 